JAMP: Jurnal Adminitrasi dan Manajemen Pendidikan

Volume 4 Nomor 1 Maret 2021, Hal : 10 - 16

Tersedia Online di http://journal2.um.ac.id/index.php/jamp/

ISSN 2615-8574 (online)

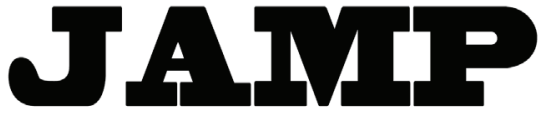

JURNAL ADMINISTRASI DAN MANAJEMEN PENDIDIKAN

\title{
TEKNOLOGI INFORMASI, PERILAKU INOVATIF, KOMPETENSI, KEPUASAN KERJA, DAN KINERJA MANAJEMEN PENDIDIKAN 4.0
}

\author{
Komang Sukadana \\ Luh Putu Mahyuni \\ Program Pascasarjana, Universitas Pendidikan Nasional \\ E-mail: sukadana084@gmail.com
}

\begin{abstract}
Industrial revolution 4.0 drives significant transformation to all sectors, including the education sector. Head of school plays significant roles in transforming the education to adapt to the changes. Therefore, it is very important to understand factors explaining head of school performance in leading the school through industrial revolution 4.0. This study aims at empirically testing the relationships between information technology, inovative attitude, competency, work satisfaction, and performance of head of school. Quantitative approach was used to answer research questions. As many as 110 questionnaires were collected and analyzed by using Structural Equation Modeling. This study indicates that informaton technology, innovative attitude, competency, significantly influence work satisfaction and performance of head of school.
\end{abstract}

Keywords: Information technology; innovative attitude; competency; work satisfaction; performance; head of school; education 4.0

\begin{abstract}
Abstrak: Revolusi industri 4.0 mendorong terjadinya perubahan signifikan pada berbagai sektor, termasuk pendidikan. Kepala sekolah merupakan ujung tombak manajemen pendidikan 4.0, sangat penting memahami faktor yang mempengaruhi kinerja mereka. Penelitian ini bertujuan untuk menguji bagaimana teknologi informasi, perilaku inovatif, kompetensi, dan kepuasan kerja mempengaruhi kinerja kepala sekolah. Untuk mencapai tujuan penelitian, digunakan pendekatan kuantitatif melalui penyebaran kuesioner kepada 110 kepala sekolah. Data dianalisis dengan Structural Equation Modelling (SEM). Penelitian ini mengindikasikan bahwa teknologi informasi, perilaku inovatif dan kompetensi memiliki dampak yang positif signifikan terhadap kepuasan kerja dan kinerja kepala sekolah. Kontribusi penelitian ini bagi literatur adalah memperkuat teori bahwa kompetensi, teknologi informasi dan perilaku inovatif berpengaruh terhadap kepuasan dan kinerja kepala sekolah.
\end{abstract}

Kata kunci: Teknologi informasi; perilaku inovatif; kompetensi; kepuasan kerja; kinerja; kepala sekolah; pendidikan 4.0

Saat ini seluruh sektor kehidupan tidak terkecuali sektor pendidikan telah dilanda Pandemi Covid-19 yang telah merubah seluruh tatanan kehidupan termasuk pendidikan. Pada masa Pandemi Covid-19 ini sekolah harus mempunyai strategi yang mampu melakukan transformasi dan inovasi guna menghadapinya. Guna menghadapi permasalahan tersebut, pimpinan sekolah dan guru diharapkan memiliki inovasi serta transformasi pembelajaran agar mampu memberikan pembelajaran yang optimal kepada peserta didik. Untuk itu lembaga pendidikan atau sekolah diharapkan telah memiliki peta perjalanan organisasi yang terintegrasi sehingga arah pengembangan bisnis dapat terlihat dengan jelas (Novitasari \& Asbari, 2020). Saat ini strategi yang paling mendesak dilakukan adalah kesiapan untuk berubah. Pandemi Covid-19 ini memaksa setiap diri dalam organisasi untuk berubah, terlebih organisasi pendidikan yang berorientasi global (Basuki, et. al. 2020). Perubahan tersebut telah mempercepat globalisasi diseluruh sektor kehidupan manusia. Untuk mampu berkompetensi diera perubahan yang begitu cepat tersebut, setiap organisasi dituntut agar mampu berkompetensi pada tatatan global. Dalam hal ini, manusia 
memiliki peran penting agar mampu berkompetensi pada tatanan global. Untuk itu setiap organisasi agar mampu memanajemeni sumber-sumber yang dimilikinya terutama human resources. Peran SDM dalam mengelola organisasi maupun perusahaan dapat dideskripsikan ke dalam teori manajemen sumber daya manusia. Dalam teori MSDM fungsi pimpinan dalam suatu organisasi ataupun perusahaan adalah menggerakkan suluruh sumber daya yang dimilikinya. Kapabilitas SDM adalah kunci terpenting dalam mewujudkan produktifitas organisasi.

Produktivitas sebuah organisasi termasuk juga dunia pendidikan sangat ditentukan oleh peran para anggota organisasinya dalam hal ini sumber daya manusianya. Kinerja sebagai efek yang diakibatkan oleh manusia sesuai standar yang ditetapkan oleh organisasi bersangkutan (As'ad Moh, 2012). Di pihak lain, Bernardin, H. J dan Russell (2013) mendefinisikan kinerja hasil hasil yang mampu dicapai oleh karyawan pada periode tertentu. Dengan demikian dapat dikatkan bahwa kinerja adalh suatu output dari suatu aktivitas yang berlangsung dalam satu periode. Begitupula halnya dengan kinerja guru dalam proses pembelajaran di sekolah. Kinerja guru merupakan perilaku guru atau kompetensi pendidik dalam melaksanakan proses pembelajaran (Gaynor, 2018).

Kinerja kepala sekolah di era revolusi industri 4.0 diharapkan berorientasi pada teknologi informasi. Kepala sekolah diharapkan memiliki kompetensi dan familier terhadap teknologi informasi. Sugiyanto dan Santoso (2018) dalam penelitiannya menemukan kompetensi dan sarana pendukung teknologi informasi berkontribusi searah dalam upaya meningkatkan kinerja karyawan. Ini artinya bahwa meningkatnya komptensi karyawan dan sarana pendukung teknologi informasi dibarengi dengan peningkatan kinerja. Penelitian yang sama juga dilakukan oleh Suhartini Eka (2017), yang meneliti tentang efek dari kompetensi dengan kinerja. Hasil penelitiannya menemukan kompetensi memiliki efek yang nyata terhadap kinerja.

Selain memiliki pengaruh langsung, kompetensi juga memiliki efek tidak langsung terhadap kinerja melalui kepuasan. Artinya kompetensi yang dibarengi dengan kepuasan akan menyebabkan efek yang semakin tinggi terhadap kinerja (Iskandar Sentot dan Juhana Enceng, 2014). Kinerja kepala sekolah selain dipengaruhi oleh komptensi serta information technology juga dipengaruhi oleh perilaku inovatf ataupun kreativitas dari individu seseorang. Performance dari kepala sekolah di era digitalisasi saat ini sangat ditentukan oleh kecerdasan ataupun inovasi dalam mengelola sumber daya yang ada. Kreativitas dapat dairtikan sebagai suatu kapabilitas individu dalam uapaya menumbuhkan ide-ide yang baru dengan cara mengkombinasikan, menerapakan ataupun mengubah yang ada menjadi hal yang baru dan bermanfaat untuk orang banyak. Ide-ide yang produktif tersebut selanjutnya diproses secara bertahap sehingga mampu menghasilkan suatu produk ataupun jasa yang memiliki nilai inovasi yang tinggi. Dama dan Ogi (2018) dalam penelitiannya menemukan inovasi serta kreatifitas secara simultan berpengaruh nyata dengan kinerja pegawai. Hasil ini tidak selaras dengan penelitian Primayana dan Lasmawan (2019) yang mana hasil penelitiannya menemukan bahwa menurut perspektif guru kebanyakan guru menyatakan bahwa kinerjanya cukup lumayan dalam kaitannya dengan pemberlakuan otonomi dan KBK sebagai bentuk inovasi pendidikan. Kendala utama yang dihadapi oleh Kepala Sekolah adalah terbatasnya sarana dan prasarana serta masih belum mapannya kualitas sumber daya pendidikan di wilayah Kecamatan Tejakula Buleleng.

Kajian kali ini dilakukan pada kepala sekolah dasar yang ada di Kabupaten Buleleng. Alasan dipilihnya kepala sekolah dasar di Kabupaten Buleleng-Bali karena fenomena yang terjadi tentang minimnya pemahaman atau kompetensi kepala sekolah di bidang teknologi informasi. Sedangkan dunia pendidikan saat ini membutuhkan peran sumber daya dalam hal ini tenaga pendidik yang memiliki pemahaman dibidang teknologi informasi. Apalagi saat ini dunia sedang dilanda Pademi Covid19 seluruh sektor kehidupan manusia dilaksanakan melalui teknologi informasi. Pimpinan lembaga pendidikan sebagai leader dan kunci keberhasilan tujuan pembelajaran yang telah dicanangkan pemerintah maupun sekolah. Saat ini, secara internal masih banyak kepala sekolah khususnya kepala sekolah dasar di Kabupaten Buleleng masih belum menguasai teknologi informasi sebagai media pembelajaran. Selain pemahaman dibidang teknologi informasi, kreativitas dan inovasi dari kepala sekolah juga masih kurang. Selain faktor internal, faktor eksternal seperti sarana dan infrastruktur teknologi informasi juga masih kurang. Kajian ini bertujuan untuk mengetahui pengaruh kompetensi, teknologi informasi, dan perilaku inovatif terhadap kepuasan dan kinerja kepala sekolah. 


\section{METODE}

Kajian ini dirancang dengan pendekatan kuantitatif, yaitu kasualitas atau hubugan sebab akibat variabel teknologi informasi, kompetensi dan perilaku inivatif dengan kepuasan kerja dan kinerja kepala sekolah. Subjek penelitian adalah Kepala SD di Kabupaten Buleleng-Bali. Instrumen yang digunakan dalam kajian ini adalah kuesioner, dengan sampel 110 orang. Sehungan dengan adanya pandemic covid-19, maka pengumpulan data memanfaatkn google form. Analisis data menggunakan SEM dengan software AMOS.

\section{HASIL}

Analisis faktor konfirmasi dilakukan untuk menguji variabel-variabel manifes pembentuk variabel laten. Selain itu analisis CFA ini juga untuk mengukur tingkat validitas variabel-variabel manifes. Sebuah indikator atau variabel di kiatakan valid apabila memiliki koefesien lamda lebih besar atau sama dengan nol koma lima dan nilai kritis atau Critical Raio lebih besar sama dengan dua koma nol serta probabilitas lebih kecil dari lima persen. Hasil analisis konfirmasi faktor masing-masing variabel dijelaskan seperti berikut.

Hasil analisis CFA variabel kompetensi seperti menunjukkan ke lima indikator variabel kompetensi memiliki nilai Standardized Estimate Regression Weight $(\lambda)$ lebih besar dari 2,00, sehingga seluruh indikator valid. Analisis CFA variabel teknologi informasi menunjukkan ke tiga indikator teknologi informasi memiliki nilai Standardized Estimate Regression Weight $(\lambda)$ lebih besar dari 2,00, sehingga ketiga indikatr valid. Hasil CFA perilaku inovatif menunjukkan ke lima indikator perilaku inovatif memiliki nilai Standardized Estimate Regression Weight $(\lambda)$ lebih besar dari 2,00, sehingga keliam indikator valid. Hasil CFA kepuasan kerja menunjukkan ke empat indikator kepuasan kerja memiliki nilai Standardized Estimate Regression Weight $(\lambda)$ lebih besar dari 2,00, sehingga keempat indikator valid. Hasil CFA kinerja menunjukkan ke lima indikator kinerja kepala sekolah memiliki nilai Standardized Estimate Regression Weight $(\lambda)$ lebih besar dari 2,00, sehingga kelima indikator valid. Setelah analisis CFA selanjutkan dilakukan analisis ful model seperti Tabel 1.

Tabel 1. Hasil analisis

\begin{tabular}{ccccccccc}
\hline & & & $\begin{array}{c}\text { Unstandarized } \\
\text { Estimate }\end{array}$ & $\begin{array}{c}\text { Standarized } \\
\text { Estimate }\end{array}$ & S.E. & C.R. & P & Ket \\
\hline $\mathrm{Z}$ & $<---$ & $\mathrm{X} 1$ &, 463 &, 353 &, 430 & 2,777 &, 041 & Signifikan \\
$\mathrm{Z}$ & $<---$ & $\mathrm{X} 2$ &, 891 &, 798 &, 193 & 4,626 & $* * *$ & Signifikan \\
$\mathrm{Z}$ & $<---$ & $\mathrm{X} 3$ &, 214 &, 429 &, 442 & 2,983 &, 029 & Signifikan \\
$\mathrm{Y}$ & $<---$ & $\mathrm{X} 1$ &, 186 &, 188 &, 230 &, 811 &, 417 & Tidak Signifikan \\
$\mathrm{Y}$ & $<---$ & $\mathrm{X} 3$ &, 308 &, 368 &, 236 & 2,806 &, 040 & Signifikan \\
$\mathrm{Y}$ & $<---$ & $\mathrm{Z}$ &, 387 &, 511 &, 108 & 3,594 & $* * *$ & Signifikan \\
$\mathrm{Y}$ & $<---$ & $\mathrm{X} 2$ &, 010 &, 422 &, 136 & 2,975 &, 031 & Signifikan \\
\hline
\end{tabular}

Keterangan tabel: $\mathrm{X} 1$ adalah variabel kompetensi, $\mathrm{X} 2$ variabel teknologi informasi, $\mathrm{X} 3$ variabel perilaku inovatif, $\mathrm{Z}$ variabel kepuasan kerja, $\mathrm{Y}$ variabel kinerja kepala sekolah.

Tabel 1 menunjukkan bahwa efek X1 ke Z, X2 ke Z, X3 ke Z, X3 ke Y, Z ke Y dan X2 ke Y memiliki nilai kritis di atas 2,000 serta nilai Prob di bawah 0,5 , sehingga memiliki pengaruh yang nyata atau signifikan. Variabel X1 ke Y memiliki nilai kritis di bawa 2,000 dan nilai Prob lebih besar 0,5 sehingga $\mathrm{X} 1$ berkontribusi tidak signifikan terhadap Y.

Tabel 2. Pengaruh Tidak Langsung

\begin{tabular}{lccc}
\hline & Perilaku Inovatif & Teknologi Informasi & Kompetensi \\
\hline Kepuasan kerja &, 000 &, 000 &, 000 \\
Kinerja kepala sekolah &, 219 &, 408 &, 180 \\
\hline
\end{tabular}

Kontribusi perilaku inovatif terhadap kinerja kepala sekolah melalui kepuasan kerja sebesar 0,219 . Kontribusi teknologi informasi terhadap kinerja kepala sekolah melalui kepuasan kerja sebesar 0,408, dan kontribusi kompetensi terhadap kinerja kepala sekolah melalui kepuasan kerja sebesar 0,180 , lihat Tabel 2. 


\section{Analisis Gof (Goodness of Fit)}

Hasil analisis Goodness of Fit, dari delapan kriteria empat kriteria telah terpenuhi. Keempat kriteria tersebut adalah chi-square dengan nilai 2,335 lebih kecil dari 3, RMSEA dengan nilai 0,046 lebih kecil dari 0,08, CFI dengan nilai 0,975 lebih besar dari 0,950 dan TLi dengan nilai 0,956 lebih besar dari 0,950 . Dengan demikian model telah memenuhi syarat yang telah ditentukan.

\section{PEMBAHASAN}

Kompetensi, TI serta perilaku inovatif memiliki peran atau kontribusi yang nyata dalam meningkatkan kepuasan pendidikan dalah hal ini kepala sekolah. kontribusi yang nyata dan searah dengan kepuasan. Ini bermakna bahwa kompetensi yang dimiliki kepala sekolah mampu meningkatkan kepuasan kerja. Tingginya kompetensi akan dibarengi dengan semakin tingginya kepuasan kerja. Indikator utama dari kompetensi yaitu motif yang dimiliki kepala sekolah untuk mencapai tujuan sekolah. Indikator memiliki nilai standardized estimate regression weight paling tinggi yaitu sebesar 0,871 . Tingginya kompetensi kepala sekolah berpengaruh terhadap kepuasan kerja terutama puas terhadap pekerjaannya. Indikator ini memiliki niliai standardized estimate regression weight paling tinggi, yaitu 0,860 , dengan demikian hipotesis nol ditolak dan menerima hipotesis penelitian yang diajukan. Hasil penelitin ini selaras dengan penelitian Sugiyanto dan Santoso (2017), Bogner dan Thomas dalam Sari (2013) yang menemukan komptensi berpengaruh positif tehadap kepuasan. Triwiyanto (2019) menyatakan hasil uji kompetensi kepala sekolah tahun 2015 bahwa nilai rata-rata per dimensi, terutama supervisi memiliki rata-rata paling rendah (36.45) dan tertinggi manajerial (48.87).

Teknologi informasi memiliki kontribusi yang nyata dan searah dengan kepuasan kerja. Penggunaan teknologi informasi oleh kepala sekolah mampu meningkatkan kepuasan kerja. Keefektifan kepla sekolah dalam menggunakan tekonologi informasi, berimbas pada semakin tingginya kepuasan kerja. Indikator utama dari teknologi informasi adalah kesesuaian antara pekerjaan dengan tools yang terdapat pada teknologi informasi. Indikator ini memiliki nilai standardized estimate regression weight paling tinggi yaitu sebesar 0,981 . Tingginya implementasi penggunaan teknologi oleh kepala sekolah berpengaruh terhadap kepuasan kerja terutama puas terhadap pekerjaannya. Indikator ini memilki nilai standardized estimate regression weight paling tinggi, yaitu sebesar 0,860 , dengan demikian hipotesis nol dotolak dan menerima hipotesis penelitian. Penelitian ini selaras dengan penelitian Dahlius dan Ibrahim (2016) dan Ida Rosnidah (2010) teknologi informasi memiliki efek yang nyata dan searah dengan kepuasan kerja.

Perilaku inovatif dari kepala sekolah memiliki kontribusi yang nyata serta searah dengan kepuasan kerja. Semakin inovasi perilaku dari pimpinan sekolah, maka akan semakin puas dalam bekerja. Indikator utama dari perilaku inovatif kepala sekolah adalah memiliki pemikiran kritis untuk mewujudkan ide-ide baru. Indikator ini memiliki nilai standardized estimate regression weight paling tinggi yaitu sebesar 0,883 . Tingginya perilaku inovasi kepala sekolah berpengaruh terhadap kepuasan kerja terutama puas terhadap pekerjannya. Indikator ini memiliki niliai standardized estimate regression weight paling tinggi, yaitu sebesar 0,860. Dengan demikian hipotesis ketiga yang menyatakan semakin baik perilaku inovatif, maka semakin tinggi kepuasan kerja kepala sekolah diterima atau teruji kebenarannya. Penelitian ini selaras dengan penelitian Sujarwo dan Wahjono (2017) perilaku inovatif mempunyai pengaruh positif kepada kepuasan kerja.

Kompetensi berkontribusi tidak nyata namun searah dengan kinerja. Tidak signifikannya peranan kompetensi dalam meningkatkan kinerja, akibat dari sebagian besar pekerjaan kepala sekolah telah dilakukan oleh staf yang berkompeten serta dibantu oleh guru-guru yang relatif muda. Oleh sebab itu komptensi yang dimiliki oleh kepala sekolah, baik dari segi pengetahun ataupun keterampilannya tidak memiliki dampak yang nyata terhadap aktivtasnya. Indikator utama dari kompetensi kepala sekolah adalah adalah motif yang dimiliki kepala sekolah untuk mencapai tujuan sekolah. Karena indikator ini memiliki nilai standardized estimate regression weight paling tinggi yaitu sebesar 0,871 . Sedangkan indikator tertinggi dari kinerja kepala sekolah adalah kuantitas kerja dengan nilai standardized estimate regression weight 0,933 , dengan demikian hipotesis nol diterima dan menolak hipotesis penelitian yang diajukan. Penelitian ini selaras dengan penelitian (Agustina \& Yuliani, 2006) kompetesi rendah akan 
mengakibatkan rendahnya prestasi siswa. Hasan (2017) kompetensi profesional guru berkorelasi lemah dengan kinerja guru.

Information technology atau teknologi informasi (TI) berkontribusi searah serta nyata efeknya terhadap kinerja. Penggunaan TI yang efektif memiliki kontribusi yang besar menumbuhkan kinerja. Semakin efektif kepala sekolah menggunakan TI, maka semakin tinggi kinerjanya. Indikator utama dari teknologi informasi adalah kesesuaian antara pekerjaan dengan tools yang terdapat pada teknologi informasi. Indikator ini memiliki nilai standardized estimate regression weight paling tinggi yaitu sebesar 0,981 . Tingginya implementasi penggunaan teknologi oleh kepala sekolah berimbas pada kinerja dalam hal ini kuantitas kerja karena memilki nilai standardized estimate regression weight paling tinggi, yaitu 0,933 , dengan demikian hipotesis nol ditolak dan menerima hipotesis penelitian. Penelitian ini selaras Sugiyanto dan Santoso (2017), Sukartha, dkk. (2015), Simanjutak (2011) teknologi informasi berkontribusi searah serta nyata terhadap kinerja.

Perilaku inovatif berkontribusi nyata serta searah dengan kinerja. Seseorang dengan inivasi yang tinggi akan berimplikasi pada hasil kerjanya. Semakin berinovasi seseorang, maka akan semakin meningkat pula kinerjanya. Indikator utama dari perilaku inovatif kepala sekolah adalah memiliki pemikiran kritis untuk mewujudkan ide-ide baru. Indikator ini memiliki nilai standardized estimate regression weight paling tinggi yaitu sebesar 0,883 . Tingginya perilaku inovasi kepala sekolah berpengaruh terhadap kinerjanya terutama kuantitas kerja karena memilki niliai standardized estimate regression weight paling tinggi, yaitu 0,933 , dengan demikian hipotesis nol ditolak dan menerima hipotesis penelitian. Penelitian ini selaras dengan penelitian Dama dan Ogi (2018), Sujarwo dan Wahjono (2017) inovasi memiliki kontirbusi yang nyata terhadap kinerja.

Kepuasan kerja berkontribusi nyata serta positif dengan kinerja. Seseorang yang memiliki kepuasan dalam bekerja menyebabkan kinerjanya optimal. Semakin puas seseorang terhadap pekerjaanya kemudian akan diikuti dengan meningkatnya hasil kerja. Indikator utama dari kepuasan kerja kepala sekolah adalah puas terhadap pekerjaannya. Indikator ini memiliki nilai standardized estimate regression weight paling tinggi yaitu sebesar 0,860 . Tingginya kepuasan kerja dari kepala sekolah berpengaruh terhadap kinerjanya terutama kuantitas kerja karena memilki niliai standardized estimate regression weight paling tinggi, yaitu 0,933 . Hasil ini menolak hipotesis nol, dan menerima hipotesis penelitian. Hasil ini selaras dengan penelitian Sujarwo dan Wahjono (2017), Iskandar dan Juhana (2014) menemukan kepuasan berkontribusi nyata terhadap kinerja pendidik atau guru.

\section{SIMPULAN DAN SARAN}

\section{Simpulan}

Hasil penelitian menjelaskan bahwa kompetensi, TI, serta perilaku inovatif berkontribusi nyata terhadap kepuasan kerja. Hasil ini bermakna bahwa kepala sekolah yang memiliki kecapkapan yang tinggi sebagai pimpinan majaerial, yang didukung dengan sarana dan prasarana TI dan diikuti oleh inovasi akan mempu meningkatkan kepuasan dalam bekerja. Kajian ini juga menemukan bahwa TI, perilaku inivatif serta kepuasan memiliki kontribusi yang nyata dalam pencapaian hasil kerja kepala sekolah. Akan tetapi komptensi yang dimiliki oleh pimpinan manajerial di sekolah dalam hal ini kepala sekolah tidak berkontribusi nyata terhadap kinerja.

\section{Saran}

Perlunya peningkatan kompetensi TI serta perilaku inovatif yang peran atau kontribusi yang nyata dalam meningkatkan kepuasan pendidikan dalah hal ini kepala sekolah. Kontribusi yang nyata dan searah dengan kepuasan. Ini bermakna bahwa kompetensi yang dimiliki kepala sekolah mampu meningkatkan kepuasan kerja. Tingginya kompetensi akan dibarengi dengan semakin tingginya kepuasan kerja. 


\section{DAFTAR RUJUKAN}

Agustina, H., and Yuliani, I. (2006) 'Faktor-faktor yang mempengaruhi kinerja guru matematika dalam pelaksanaan kurikulum berbasis kompetensi (KBK) pada sekolah menengah atas Kota Palembang', Jurnal Bisnis Dan Manajemen, 4(7), pp. 24-31.

Antasari, K. C., and Sukartha, P. D. Y. (2015) 'Pengaruh efektivitas sistem informasi akuntansi dan penggunaan teknologi informasi pada kinerja individual dengan kepuasan kerja sebagai variabel pemoderasi’, E-Jurnal Akuntansi, 10(2), pp. 354-369.

As'ad, M. (2012). Psikologi industri, seri ilmu sumber daya manusia. Jakarta: Salemba Empat.

Bernardin, H. J. dan Russell, J. E. A. (2013). Human Resource Management. New York: McGrawHill.

Basuki, S., Asbari, M., Fayzhall, M., Goestjahjanti, F. S., Winanti, Yuwono, T., Hutagalung, D., Maesaroh, S., Mustofa, Chidir, G., Yani, A., and Purwanto, A. (2020) 'Peran kepemimpinan transformasional dan organisasi pembelajaran terhadap kapasitas inovasi sekolah', EduPsyCouns: Journal of Education, Psychology and Counseling, 2(1), pp. 6724-6748.

Dama, J. and Ogi, I.W.J. (2018) 'Pengaruh inovasi dan kreativitas terhadap kinerja karyawan Pada PT. Bank Mandiri (Persero) Tbk', Jurnal EMBA, 6(1), pp. 41-50.

Fajrillah, F., Purba, S., Sirait, S., Sudarso, A., Sugianto, S., Sudirman, A., Febrianty, F., Hasibuan, A., Julyanthry, J., and Simarmata, J. (2020). Smart entrepreneurship: peluang bisnis kreatif \& inovatif di era digital. Jakarta: Yayasan Kita Menulis.

Ferdinand, A. (2014). Metode penelitian manajemen. Semarang: Universitas Diponegoro.

Gaynor. (2018). Innovation by desig. New York: American Management Association.

George, J. M., and Zhou, J. (2001) 'When openness to experience and conscientiousness are related to creative behavior: an interactional approach', Journal of Applied Psychology, 86(3), pp. 502-513.

Gibson, E. al. (2015). Organisasi : perilaku, struktur, proses. Jakarta: Erlangga.

Hamzah, B. U. (2010). Teknologi komunikasi dan informasi pembelajaran. Jakarta: Bumi Aksara.

Handoko, T. H. (2014). Manajemen personalia dan sumber daya manusia. Yogyakarta: BPFE.

Iskandar, S., and Juhana, E. (2014) 'Pengaruh kompetensi dan lingkungan kerja terhadap kepuasan kerja serta implikasinya pada kinerja guru di SDN Baros Mandiri 5 Kota Cimahi’, Jurnal Ekonomi, Bisnis \& Entrepreneurship, 8(2), pp. 86-98.

Jogiyanto, H. M. (2010). Teori portofolio dan analisis investasi. Edisi Ketujuh. BPFE. Yogyakarta.

Mangkunegara, A. A. P. (2010). Evaluasi kinerja SDM. Bandung: Refika Aditama.

Mathis, R. L. and Jackson, J.H. (2016). Manajemen sumber daya manusia. Jakarta: Salemba Empat.

Munir. (2008). Kurikulum berbasis teknologi informasi dan komunikasi. Bandung: Alfabeta.

Novitasari, D. and Asbari, M. (2020) 'Peran kesiapan untuk berubah terhadap kinerja guru di masa pandemi covid-19', Journal Industrial Engineering \& Management Research (JIEMAR). 1(2). pp. 219-237.

Priansa, D. J. (2014). Perancangan dan pengembangan sumber daya manusia. Bandung: Alfabeta.

Primayana K. H., and Lasmawan I K. (2019) 'Pengaruh model pembelajaran kontekstual berbasis lingkungan terhadap hasil belajar IPA di tinjau dari minat outdoor pada siswa kelas IV', Jurnal Pendidikan Dan Pembelajaran IPA Indonesia, 9(2), pp. 72-79.

Qamari, I. N., Dewayani, J., Frianto, A., Nugroho, M., Mulyantomo, E., Setyowati, R., and Sudjatmoko, P. (2014). Telaah buku perilaku organisasi dan pengembangan organisasi. Yogyakarta: Lembaga Penelitian, Publikasi, dan Pengabdian Pada Masyarakat Universitas Muhammadiyah.

Rivai, V. S. and E. J. S. (2010). Management sumber daya manusia untuk perusahaan. Jakarta: PT. Raja Grafindo Persada.

Riyanto, L. D. P. (2011). Teknologi informasi pendidikan. Yogyakarta: Gava Media.

Sari, A. R. (2013) 'Strategi blended learning untuk peningkatan kemandirian belajar dan kemampuan critical thinking mahasiswa di era digital. Jurnal Pendidikan Akuntansi Indonesia', 11(2), pp. 22-31.

Sedarmayanti. (2011). Manajemen sumber daya manusia. Bandung: Rafika Aditama.

Simamora, H. (2016). Manajemen sumber daya manusia. Yogyakarta: BP STIE YKPN.

Simanjuntak, R. A. (2010) 'Analisis Pengaruh shift kerja terhadap beban kerja mental dengan metode subjective workload assessment technique (SWAT)', Jurnal Teknologi, 3(1), pp. 53-60.

Sinambela, L. P. (2012). Kinerja pegawai: teori pengukuran dan pmplikasi. Yogyakarta: Graha Ilmu. 
Sugiyanto, and Santoso, D. (2018) 'Analisis pengaruh kompetensi, sarana pendukung teknologi informasi dan kepuasan kerja sebagai variabel intervening terhadap kinerja SDM. Jurnal, Magister Manajemen Universitas Semarang, 22(1), pp. 76-92.

Sugiyono. (2015). Metode penelitian pendidikan (pendekatan kuantitatif, kualitatif dan $R \& D$ ). Bandung: Alfabeta. Suhartini, E. (2017) 'Pengaruh kompetensi terhadap kinerja pegawai (studi perbandingan antara Fakultas Ekonomi dan Bisnis Islam dan Fakultas Syariah dan Hukum Uinam)', Jurnal UIN Alauddin, 8(2), pp. 61-78.

Suwatno and Prianda, D. J. (2011). Manajemen SDM dalam organisasi dan bisnis. Bandung: Alfabeta.

Suyanto, M. (2005). Pengantar teknologi informasi untuk bisnis. Yogyakarta: Andi.

Tohardi, A. (2009). Pemahaman praktis manajemen sumber daya manusia. Bandung: Mandan Maju.

Triwiyanto, T. (2019). Gelombang Liberalisme Pendidikan Mengawal Tata Kelola Pendidikan Untuk Rakyat. Jakarta: Kompas.

Wahjono, S. A. (2017) 'Pengaruh motivasi kerja dan perilaku inovatif terhadap kinerja karyawan dengan kepuasan kerja sebagai variabel mediasi (studi kasus pada LKP Alfabank Semarang)', Jurnal Infokom, 4(2), pp. 63-71.

Wibowo. (2017). Budaya organisasi : sebuah kebutuhan untuk meningkatkan kinerja jangka panjang. Jakarta: Rajawali Pers.

Wirawan, I G. P. N. G. P. N. (2016). Statistika ekonomi dan bisnis (statistika deskriptif). Denpasar: Keraras Emas. 